\title{
Neue Arzneimittel, Spezialitäten und Geheimmittel.
}

Von Dr. Franz Zernik in Steglitz.

XIX.

Unter dem Namen Hydropyrin wurde von der Chemischen Fabrik Gedeon Richter in Budapest im Jahre 1907 das Natriumsalz der Acetylsalizylsäure, $\mathrm{C}_{6} \mathrm{H}_{4}<\underset{\mathrm{COONa}}{\mathrm{O} . \mathrm{COCH}_{8}}$, in den Handel gebracht, "eine neutrale und daher von allen Reizwirkungen freie Verbindung“, die "vor dem Aspirin den Vorzug der Wasserlöslichkeit" hat und wie jenes gegeben werden soll. Die vor etwa einem Vierteljahre vorgenommene Untersuchung ergab jedoch, daß Hydropyrinpulver wie Hydropyrintabletten in erheblichem Maße zersetzt waren. Die Präparate rochen stark nach Essigsäure; beim Auflösen hinterblieb ein aus Salizylsäure und Acetylsalizylsäure bestehender, ungelöster Rückstand: aus dem ursprünglich vorhanden gewesenen acetylsalizylsauren Natrium hatte sich zuerst Essigsäure abgespalten unter gleichzeitiger Bildung von salizylsaurem Natrium, und diese Abspaltung freier Essigsäure bewirkte dann natürlich weiter, daß sich beim Auflösen des Hydropyrins durch Umsetzung freie Salizylsäure bzw. Acetylsalizylsäure abschieden, die in Wasser schwer löslich sind, während essigsaures Natrium in Lösung ging. Das untersuchte Hydropyrin enthielt rund $10 \%$ so entstandenes essigsaures Natrium neben salizylsaurem und acetylsalizylsaurem Natrium. Die Ursache zu dieser Zersetzung ist darin zu suchen, daß das Präparat sehr hygroskopisch ist und daß die Wasseraufnahme dann die erwähnten chemischen Vorgänge einleitet. Die darstellende Firma erklärte nunmehr, es habe sich in dem vorliegenden Falle um ältere Präparate gehandelt, wie sie anfänglich in den Vtrkehr gelangt seien - (warum überhaupt? Ref.) das neuerdings im Handel befindliche Präparat sei infolge anderer Darstellungsmethoden nicht zersetzt und auch nicht hygroskopisch. Die erneute Untersuchung konnte indes diese Behauptung nur zum Teil bestätigen; auch das neue, an sich klar lösliche Hydropyrin zieht mit großer Begierde Wasser an, und damit ist dann gleichzeitig auch die Veranlassung zu den oben geschilderten Zersetzungs. vorgängen gegeben. Die Beständigkeit des acetylsalizylsauren $\mathrm{Na}$ triums ist somit eine sehr bedingte und demzufolge auch die Möglichkeit seiner arzneilichen Verwertung.

Indoform (in Amerika Gen of orm genannt) ist die "neueste $\mathrm{Er}$ findung zur Bekämpfung von Gicht, Ischias, Rheumatismus, Influenza, Neuralgie, Kopf- und Zahnschmerz“... „Das Indoform ist eine ihrer schädlichen Nebenwirkungen entkleidete Salizylsäureverbindung, die nicht allein die vorzüglichen spezifischen Eigenschaften

1) Ein Universalstativ für Röntgenröhren von Dr. Davidsohn. Deutsche medizinische Wochenschrift No, 26 
dieser Säure beibehalten hat, sondern noch um neue, außerordentlich wertvolle Wirkungen bereichert worden ist. Solch überraschende Erfolge wurden dadurch erzielt, daß das Indoform (eine Verbindung von Salizylsäure mit Essigsäure und Formaldehyd, d. i. Salizylsäuremethylenacetat) erst im Darm zur Entfaltung seiner Wirksamkeit gelangt. Diese wichtige Eigenschaft in Verbindung mit der Abspaltung von Formaldehyd, dem kräftigsten Desinfiziens, das wir derzeit besitzen, bedingen den therapeutischen Wert des Indoforms“. . Dosis 0,5 g 3 mal täglich. Nach den Angaben der darstellenden Fabrik, Fritz Schulz in Leipzig, ist dieses Indoform ein einheitlicher Körper vom Schmelzpunkt 108-109, der durch „Kondensation von Formaldehyd und Acetylsalizylsäure unter bestimmten Bedingungen ${ }^{\alpha}$ entsteht und die Formel $\mathrm{C}_{8} \mathrm{H}_{4}<\mathrm{O} \cdot \mathrm{CH}_{2} \cdot \mathrm{COCH}_{3}$

besitzt. Frerichs hat demgegenüber nachgewiesen, daß Indoform lediglich ein Ge misch ist aus rund einem Drittel Salizylsäure und zwei Dritteln Acetylsalizylsäure, das außerdem gerade eben nachweisbare Spuren irgendeiner Formaldehydverbindung enthält, deren $\mathrm{Zu}-$ sammensetzung nicht zu ermitteln ist, und wahrscheinlich Spuren ron Salizylsäuremethylester. Ueber die Art der Darstellung lassen sich nur Vermutungen aussprechen; nach dem in der Patentanmeldung angegebenen Verfahren erhält man weder ein Präparat von der fiktiven noch von der tatsächlichen Zusammensetzung des Indoforms. Recht eigentümlich berührt es dem unerbittlichen Analysenbefund gegenüber, wenn in verschiedenen ärztlichen Abhandlungen die vorzügliche Wirkung des de facto gar nicht vorhandenen Formaldehyds gepriesen wird, z. B. als eines Harnsäure lösenden Mittels!

„Laïn ist ein merkwürdiges Mittel, das schnell und erfolgreich Ekzema, Flechten, Hautausschläge, Wunden, Beinwunden, offene Füße, Brandmale, Geschwüre, Entzündungen, Sehnenerweiterung, aufgesprungene Haut und ähnliche Krankheiten der Haut heilt. Das Jucken und der Schmerz verschwindet fast auf der Stelle. Es ist ferner ein vorzügliches Mittel gegen Podagra, Ischias und Neuralgie, wobei der Schmerz schnellstens gelindert wird." Das Präparat wird hergestellt und vertrieben von der Laïn-Gesellschaft m. b. H., Berlin W66., Wilhelmstraße 45. Preis per Dose 3,90 M exklusive Porto. Eine solche Dose enthält etwa $35 \mathrm{~g}$ einer grauweißen Salbe; als deren Bestandteile wurden festgestellt gleiche Teile Zinkoxyd und Naftalan oder ein dem Naftalan ähnliches, Natronseife enthaltendes, hochsiedendes Erdöldestillat. Der Preis ist als unverhältnismäßig hoch zu bezeichnen; nach der Arzneitaxe berechnet, würde ein derartiges mit Naftalan bereitetes Gemisch alles in allem noch nicht eine Mark kosten. 